\title{
From the desk of Editor-in-Chief
}

doi: http://dx.doi.org/10.3329/jemc.v7i2.32648

Alhamdulillah! We are already in the $7^{\text {th }}$ year of successful publication of Journal of Enam Medical College and the journal is indexed in more than a dozen indexing databases. We share this success with the contributors, reviewers and faculties and authority of the college without whose active and sincere cooperation it would not have been possible to publish the journal regularly and timely.

The flow of paper submission for publication in the Journal of Enam Medical College continues to be very good. Papers are flowing from both home and abroad. This has been because of the quality of the journal and regular and timely publication.

In this issue we have published an important paper titled 'Identifying Predatory or Pseudo-Journals'. The World Association of Medical Journal Editors (WAME) Board has recently announced the publication of the WAME statement on Identifying Predatory or Pseudo-Journals (posted on February 18, 2017). Members of WAME are permitted to republish the statement in their journals. As Editor-in-Chief and Editor of Journal of Enam Medical College are members of WAME, we have published this important paper in Journal of Enam Medical College.

This WAME document aims to provide guidance to help editors, researchers, funders, academic institutions and other stakeholders distinguish predatory journals from legitimate journals. We hope that it will help our young researchers and authors to publish their papers in the right and legitimate journals.

With all the best wishes.

\section{Prof. Md. Aminul Haque Khan \\ Editor-in-Chief}

